\title{
Controlled supramolecular structure of guanosine monophosphate in the interlayer space of layered double hydroxide
}

\author{
Gyeong-Hyeon Gwak ${ }^{\ddagger 1}$, Istvan Kocsis ${ }^{\ddagger 2}$, Yves-Marie Legrand ${ }^{\ddagger 2}$, Mihail Barboiu*2 \\ and Jae-Min $\mathrm{Oh}^{* 1}$
}

\author{
Full Research Paper \\ Address: \\ ${ }^{1}$ Department of Chemistry and Medical Chemistry, College of Science \\ and Technology, Yonsei University, Wonju, Gangwondo, 26493, \\ Republic of Korea, and ${ }^{2}$ Adaptive Supramolecular Nanosystems \\ Group, Institut Européen des Membranes, University of \\ Montpellier/ENSCM/CNRS 5635, PI. Eugène Bataillon, CC 047, \\ 34095 Montpellier, Cedex 5, France \\ Email: \\ Mihail Barboiu* - mihail-dumitru.barboiu@univ-montp2.fr; \\ Jae-Min Oh* - jaemin.oh@yonsei.ac.kr \\ * Corresponding author $\ddagger$ Equal contributors \\ Keywords: \\ guanosine monophosphate; hydrogen bond; layered double \\ hydroxide; ribbon structure; supramolecular assembly
}

Beilstein J. Nanotechnol. 2016, 7, 1928-1935.

doi:10.3762/bjnano.7.184

Received: 28 July 2016

Accepted: 11 November 2016

Published: 06 December 2016

This article is part of the Thematic Series "Hybrid nanomaterials: from the laboratory to the market".

Guest Editor: A. Taubert

(C) 2016 Gwak et al.; licensee Beilstein-Institut.

License and terms: see end of document.

\begin{abstract}
Guanosine monophosphates (GMPs) were intercalated into the interlayer space of layered double hydroxides (LDHs) and the molecular arrangement of GMP was controlled in LDHs. The intercalation conditions such as GMP/LDH molar ratio and reaction temperature were systematically adjusted. When the GMP/LDH molar ratio was 1:2, which corresponds to the charge balance between positive LDH sheets and GMP anions, GMP molecules were well-intercalated to LDH. At high temperature (100 and $80{ }^{\circ} \mathrm{C}$ ), a single GMP molecule existed separately in the LDH interlayer. On the other hand, at lower temperature (20, 40 and $\left.60{ }^{\circ} \mathrm{C}\right)$, GMPs tended to form ribbon-type supramolecular assemblies. Differential scanning calorimetry showed that the ribbon-type GMP assembly had an intermolecular interaction energy of $\approx 101 \mathrm{~kJ} / \mathrm{mol}$, which corresponds to a double hydrogen bond between guanosine molecules. Once stabilized, the interlayer GMP orientations, single molecular and ribbon phase, were successfully converted to the other phase by adjusting the external environment by stoichiometry or temperature control.
\end{abstract}

\section{Introduction}

Since Bernal [1] and Cairns-Smith [2] suggested that layered clays contributed to the origin of life by affecting the conformation of prebiotic molecules in ancient environment, many scien- tists have begun to focus their research on the molecular arrangement of biological substances in the interlayer space of layered inorganics $[3,4]$. In those investigations, monomeric 
prebiotic molecules such as amino acid, nucleoside or nucleotide were intercalated and it was suggested that the geometrical restriction of molecules under the confined interlayer space of inorganics would aid the polymerization of biological molecules.

Mann et al. intercalated two kinds of amino acids, aspartate and glutamate, into layered double hydroxide (LDH) to synthesize bioinorganic nanocomposites [5]. Post-synthetic thermal treatment resulted in polymerization of amino acids in LDH. It was also reported that amino acids such as arginine and glutamate were polymerized via peptidic condensation both on the surface and in the interlayer space of clay [6]. In that literature, peptidic condensation of amino acids was determined to favor heteropeptide rather than homopeptide. Besides polymerization of amino acids, it was reported that abiotic oligomerization of RNA nucleotides was catalyzed by montmorillonite clay [7]. In the presence of clay, the length of polymerized RNA oligonucleotides was three times longer than without clay.

Among biological molecules, guanosine derivatives are known to have various supramolecular assembly routes through intermolecular interactions. For instance, telomere in chromosome consists of stacks of guanosine quartets (G4), in which four guanosines are linked through hydrogen bonds in the presence of $\mathrm{K}^{+}$ions. There have been many attempts to synthesize guanosine-based supramolecular assemblies such as ribbon or quadruplex. Spada et al. verified that two kinds of ribbon structures could be obtained by self-assembly of lipophilic deoxyguanosine derivatives through hydrogen bonding [8]. They suggested those supramolecular nucleoside structures could be utilized for molecular nanowire fabrication or molecular electronics. Davis et al. prepared stable G4 hydrogels utilizing guanosine, potassium and borate [9]. Those hydrogels exhibited specific binding ability towards cationic dyes or nucleoside through noncovalent interactions. Due to its characteristic structure having $\mathrm{K}^{+}$in the center, G4 quartets can be considered as scaffolds for artificial ion channels. We have reported a stable G4 membrane film utilizing guanosine and bis(3-aminopropyl)polytetrahydrofuran [10]. These G4 membranes showed potential in $\mathrm{Na}^{+} / \mathrm{K}^{+}$artificial ion channels.

Inspired by the above reports claiming that i) intermolecular interactions of biomolecules are strongly affected by the confined geometry of layered clays and that ii) guanosine derivatives form various supramolecular assemblies, depending on the chemical environment, we hypothesized that the orientation of guanosine derivatives can be controlled in the restricted nanospace of layered inorganics. In this study, we utilized layered double hydroxides (LDH), which are composed of positively charged layers $\left(\mathrm{Mg}_{2} \mathrm{Al}(\mathrm{OH})_{6}{ }^{+}\right)$with equivalent area per charge $\approx 25 \AA^{2} /(+)$ and charge compensating interlayer anions $[11,12]$. As it is known that interlayer anions in LDH can be easily exchanged by external anions, and that once introduced, anions are stabilized via electrostatic interaction [13,14], we utilized guanosine monophosphate (GMP) as a model molecule. First, we prepared LDHs with exchangeable anions and intercalated GMP through an ion exchange reaction. We evaluated the molecular conformation of GMP in the interlayer space of LDH by varying the GMP/Al ${ }^{3+}$ (in $\mathrm{LDH}$ ) molar ratio and the reaction temperature. This was revealed that GMP molecules are separated or assembled into ribbons depending on the synthetic conditions. Furthermore, we confirmed that once stabilized GMP orientation in LDH could be converted to the other state by adjusting the physicochemical environment.

\section{Results and Discussion}

In order to promote intercalation of GMP into the interlayer space of $\mathrm{LDH}$, we set the reaction temperature at $80^{\circ} \mathrm{C}$, and varied the GMP/Al ${ }^{3+}$ (in LDH) ratio to $1: 0.25,1: 0.5,1: 1,1: 2$, $1: 4$ and $1: 10$. According to the adsorption isotherm, we found that GMP adsorption (or intercalation) to LDH follows Langmuir adsorption (Supporting Information File 1, Figure S1). The theoretical anionic exchange capacity (AEC) was satisfied at GMP/LDH ratio of $1.5: 1$, while the ideal stoichiometry GMP/LDH is $1: 2$ (note that GMP is a dianion and that the chemical formula of $\mathrm{LDH}$ is $\left.\left[\mathrm{Mg}_{2} \mathrm{Al}(\mathrm{OH})_{6}\right]^{+}\left(\mathrm{NO}_{3}\right)^{-}\right)$. Figure 1 shows X-ray diffraction (XRD) patterns of GMP/LDH (GL) hybrids prepared under various GMP/LDH molar ratios. At high GMP ratio (Figure 1c-e), the XRD patterns revealed amor-



Figure 1: X-ray diffraction (XRD) patterns of products prepared by ion exchange between MgAl-LDH and GMP under controlled GMP/LDH molar ratios at $80{ }^{\circ} \mathrm{C}$ for 1 day. (a) GMP only, (b) MgAl-NO $\mathrm{NO}_{3}-\mathrm{LDH}$, (c) 1:0.25, (d) 1:0.5, (e) 1:1, (f) 1:2, (g) 1:4, (h) 1:10 (GMP/LDH). Underlined Miller indexes are $(00 /)$ of $\mathrm{NO}_{3}{ }^{-}$interlayer anion $\left(\mathrm{MgAl}-\mathrm{NO}_{3}-\mathrm{LDH}\right)$. Miller indexes without underline are $(00 /)$ of GMP intercalated LDH. 
phous structures, which was attributed to the disordered layer stacking of LDH due to the large quantity of organic moieties (GMP) as shown previously [15]. At GMP/LDH molar ratio of $1: 2$ and 1:4 (Figure 1f and Figure 1g, respectively), $(00 l)$ peaks shifted to lower angles as compared to pristine LDH, indicating ordered layer stacking with interlayer GMP moiety. However, excessive loading of LDH resulted in the decrease of intercalated peaks and increase of pristine peaks (Figure 1g,h). The optimum GMP/LDH ratio, yielding single-phased GMP intercalated $\mathrm{LDH}$, was determined to be 1:2, which was expected from the stoichiometry according to charge neutralization. From the adsorption isotherm, the GMP/LDH ratio of 1:2 resulted in $90 \%$ of GMP uptake compared to theoretical AEC. The diameter of one GMP molecule is $\approx 1,000 \AA^{3}$ and it is larger than the interlayer volume provided by the LDH (area per 2 charges $\left(50 \AA^{2}\right.$ ) $\times$ gallery height $\left.(8-13 \AA) \approx 400-650 \AA^{3}\right)$. Thus, a GMP/LDH ratio of $1: 2$ would be sufficient to accommodate as many GMP molecules as possible in the LDH interlayer space. The d-spacing of GMP intercalated LDH was calculated to be $12.6 \AA$, which was the summation of the LDH layer thickness $(\approx 4.8 \AA)$ and the perpendicular arrangement of U-shaped GMP $(\approx 7.8 \AA)$.

In order to control the interlayer GMP arrangement, we fixed GMP/LDH to $1: 2$ and varied the reaction temperature. As shown in Figure 2, the GL hybrid obtained at $100{ }^{\circ} \mathrm{C}$ showed a similar XRD pattern (Figure 2b) compared with that obtained at $80{ }^{\circ} \mathrm{C}$. On the other hand, those prepared at lower temperature $\left(20,40\right.$ and $\left.60^{\circ} \mathrm{C}\right)$ showed $(00 l)$ peaks shifted to lower angles (Figure $2 \mathrm{c}-\mathrm{e}$ ). The d-spacing values of the GL hybrid obtained at lower temperature was approximately $17.7 \AA$, which was $5.1 \AA$ larger than for the single molecular orientation. Similar to the GMP adsorption at $80{ }^{\circ} \mathrm{C}$, GMP uptake at $20^{\circ} \mathrm{C}$ followed a Langmuir model. Although the Langmuir adsorption rate at $20^{\circ} \mathrm{C}$ was slightly smaller than $80^{\circ} \mathrm{C}$, the overall adsorption patterns at the two temperatures were similar. Thus, the different interlayer space of GL hybrids at two different temperatures is thought to originate from interlayer molecular orientation of GMP. It is well known that guanosine moieties including GMP form various supramolecular structures result from its selfassembly. GMP makes quadruplex structures in the presence of specific metal as found in the telomere of chromosome [16]. Without metal cations, GMPs make ribbon-type structures through hydrogen bonding between $\mathrm{H}$ and electronegative sites ( $\mathrm{N}$ or $\mathrm{O}$ ). Two kinds of ribbon phases, I and II, have been reported [8].

Considering the molecular dimensions, the GMP intercalated to $\mathrm{LDH}$ layers at low temperature were thought to form in ribbon II supramolecular orientation (Figure 3b). At relatively high synthetic temperature, the formation of hydrogen bonds was

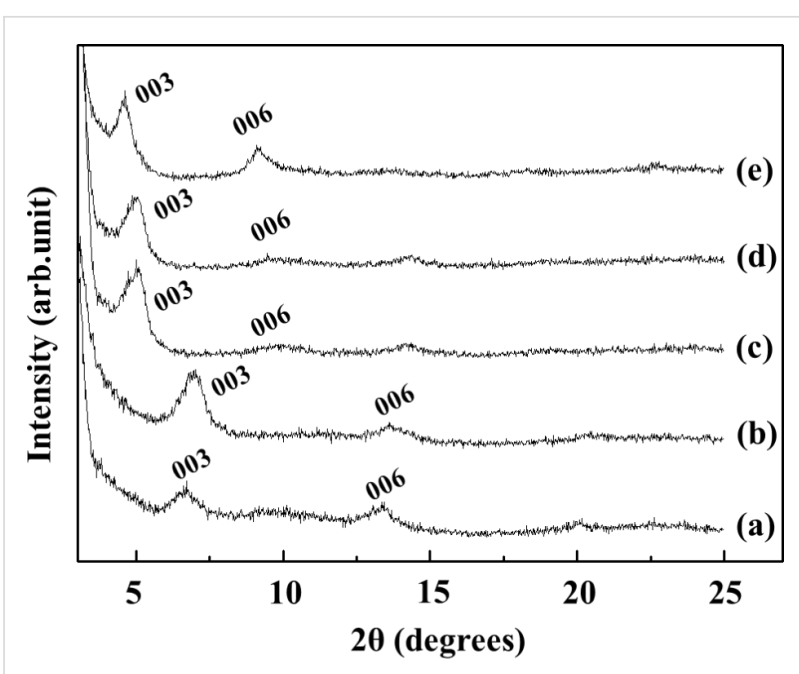

Figure 2: X-ray diffraction (XRD) patterns of GMP/LDH (GL) hybrid under controlled reaction temperature with GMP/LDH 1:2 for 1 day. (a) $100^{\circ} \mathrm{C}$, (b) $80^{\circ} \mathrm{C}$, (c) $60^{\circ} \mathrm{C}$, (d) $40^{\circ} \mathrm{C}$, (e) $20^{\circ} \mathrm{C}$.

disfavored and GMP existed as a single molecular arrangement (Figure 3a). Considering that double-helix DNA denatures to single-stranded DNA above $70{ }^{\circ} \mathrm{C}$ through hydrogen bonding breakage [17], the reaction temperature above $60{ }^{\circ} \mathrm{C}$ in this study might be sufficient to disrupt hydrogen bonding between GMPs. It was interesting to observe that the single molecular arrangement of GMP obtained at relatively high temperature was preserved between LDH layers after the material was cooled down to room temperature. Two kinds of GL hybrids with different GMP arranagements, single and ribbon, were named GL-S and GL-R, respectively.

Figure 4 shows powder XRD patterns of pristine LDH, GL-S and GL-R at the $2 \theta$ region $3-80^{\circ}$, showing clear lattice peaks at (012) and (110) for hybrids. This result showed that the lattice of LDH along $a-b$-plane direction was well preserved while there was lattice expansion along the $c$-axis resulting from molecular orientation of GMPs.

According to thermogravimetric analysis (TGA) and X-ray fluorescence (XRF) spectroscopy, the chemical formula of GL-S and GL-R were determined to be $\mathrm{Mg}_{2.00} \mathrm{Al}(\mathrm{OH})_{6}(\mathrm{G}-$ $\mathrm{MP})_{0.37}\left(\mathrm{NO}_{3}\right)_{0.26} \cdot\left(\mathrm{H}_{2} \mathrm{O}_{\text {interlayer }}\right)\left(0.63 \mathrm{H}_{2} \mathrm{O}_{\text {surface }}\right)$ and $\mathrm{Mg}_{2.00} \mathrm{Al}(\mathrm{OH})_{6}(\mathrm{GMP})_{0.42}\left(\mathrm{NO}_{3}\right)_{0.16} \cdot\left(\mathrm{H}_{2} \mathrm{O}_{\text {interlayer }}\right)\left(0.82 \mathrm{H}_{2} \mathrm{O}_{\text {surf- }}\right.$ ace), respectively. Slightly larger GMP content in GL-R as compared to GL-S could explain the formation of the ribbon arrangement of GMP in the GL-R hybrid. The area of the LDH layer, $\mathrm{Mg}_{2} \mathrm{Al}(\mathrm{OH})_{6}{ }^{+}$, is approximately $25 \AA^{2}$. Considering that the cross-sectional area of one GMP molecule is $\approx 60 \AA^{2}$, GMP occupies $22 \AA^{2}\left(60 \AA^{2} \times 0.37\right)$ and $25 \AA^{2}\left(60 \AA^{2} \times 0.42\right)$, respectively for GL-S and GL-R. Thus, the GMP moiety in GL-S could exist separately without effective intermolecular interac- 

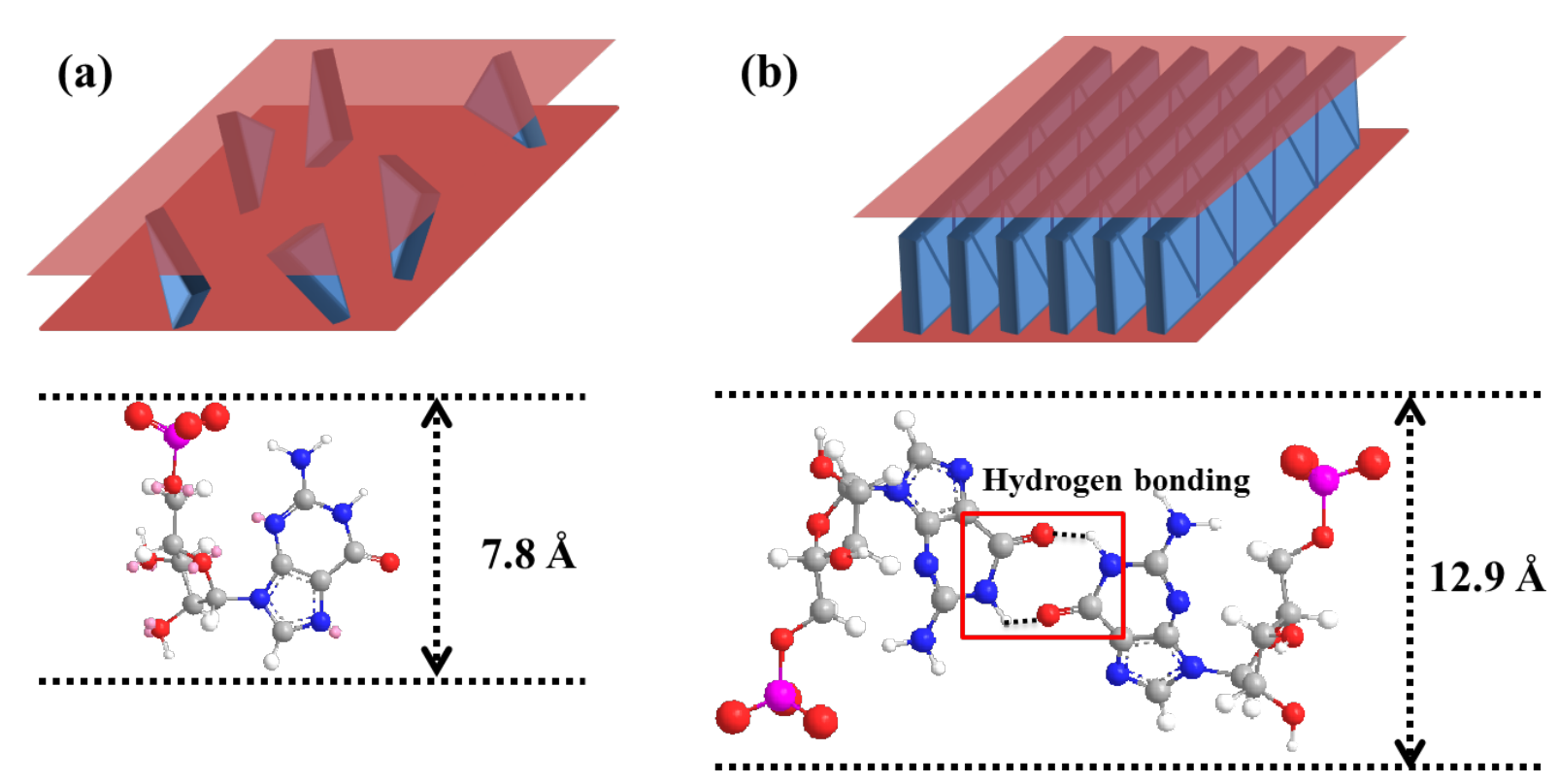

Figure 3: Schematic illustrations for interlayer structure of GMP/LDH hybrids according to molecular arrangement of GMPs: (a) single molecule arrangement (GL-S) and (b) ribbon II arrangement (GL-R).

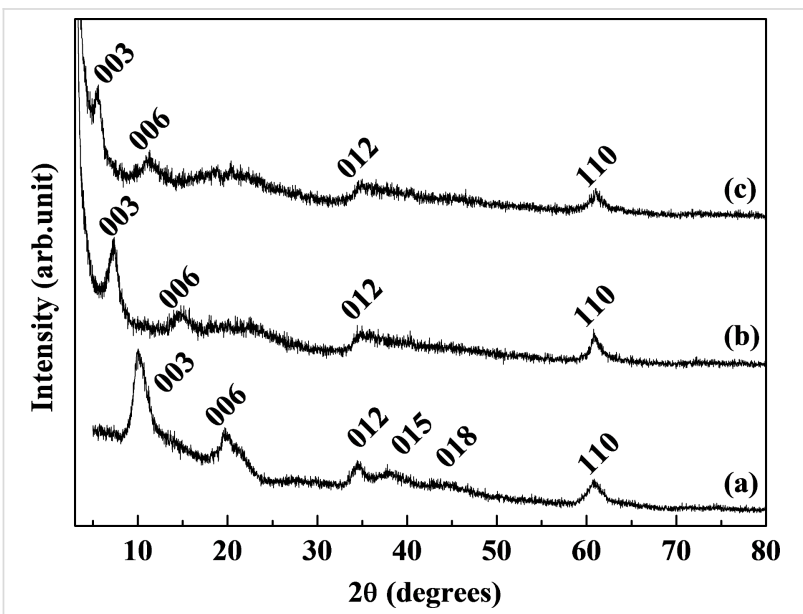

Figure 4: XRD patterns of (a) pristine MgAl-NO $3-\mathrm{LDH}$, (b) GL-S and (c) GL-R.

tion by GMP, while GMPs in GL-R packs to form a ribbon-type supramolecular arrangement.

Differential scanning calorimetry (DSC) diagrams for both GL hybrids suggested the hydrogen bonding among GMP moiety in GL-R hybrid (Figure 5). For comparison, we carried out DSC measurements of GMP only, which showed $177.33 \mathrm{~kJ} / \mathrm{mol}$ of endothermic enthalpy change at $191.28{ }^{\circ} \mathrm{C}$, indicating strong hydrogen bonding among GMP molecules. Also, we verified that the DSC diagram of pristine LDH showed an endothermic peak at $216.23{ }^{\circ} \mathrm{C}$ with an enthalpy change of $39.9 \mathrm{~kJ} / \mathrm{mol}$, which exactly matches the calculated water evaporation energy $(\approx 40 \mathrm{~kJ} / \mathrm{mol})$ of $\mathrm{Mg}_{2} \mathrm{Al}(\mathrm{OH})_{6}\left(\mathrm{NO}_{3}\right) \cdot \mathrm{H}_{2} \mathrm{O}$. Both hybrids showed a strong endothermic peak at around $200{ }^{\circ} \mathrm{C}$, which was attributed to breaking intermolecular interaction of interlayer GMP as well as evaporating interlayer water molecules. Interlayer water was evaporated from the DSC of pristine LDH at around $210^{\circ} \mathrm{C}$ with an enthalpy change of $\approx 40 \mathrm{~kJ} / \mathrm{mol}$, which was subtracted from the endothermic enthalpy of GL hybrids. The resulting intermolecular interaction between GMP was found to be $11.2 \mathrm{~kJ} / \mathrm{mol}$ GMP and $101.6 \mathrm{~kJ} / \mathrm{mol}$ GMP for GL-S and GL-R, respectively. The much higher energy for GL-R implied that there might be strong intermolecular interaction such as hydrogen bonding. According to the literature where hydrogen bonding energy between base pairs was simulated, double hydrogen bonded guanine-cytosine pair had $74-96 \mathrm{~kJ} / \mathrm{mol}$ depending on bonding orientation [18]. Thus, the intermolecular energy of $101.6 \mathrm{~kJ} / \mathrm{mol}$ (Figure $5 \mathrm{~d}$ ) might be attributed to the double hydrogen bonding between the GMP moiety as shown in Figure $3 \mathrm{~b}$. The DSC for GMP only (powder state) showed endothermic enthalpy of $177 \mathrm{~kJ} / \mathrm{mol} \mathrm{GMP}$ at $190{ }^{\circ} \mathrm{C}$, implying that there was strong intermolecular interaction and possible formation of supramolecular structure in powder GMP.

To identify the supramolecular assembly of GMPs in GL-R, we carried out ${ }^{13} \mathrm{C}$ solid state nuclear magnetic resonance (NMR) utilizing a G4 quartet supramolecular assembly as the reference (Supporting Information File 1, Figure S2). The G4 quartet showed a single set of signals due to their symmetric structure. In GL-R, the signals for the quartet slightly shifted as well as the evolution of new signals. The result suggested that the 

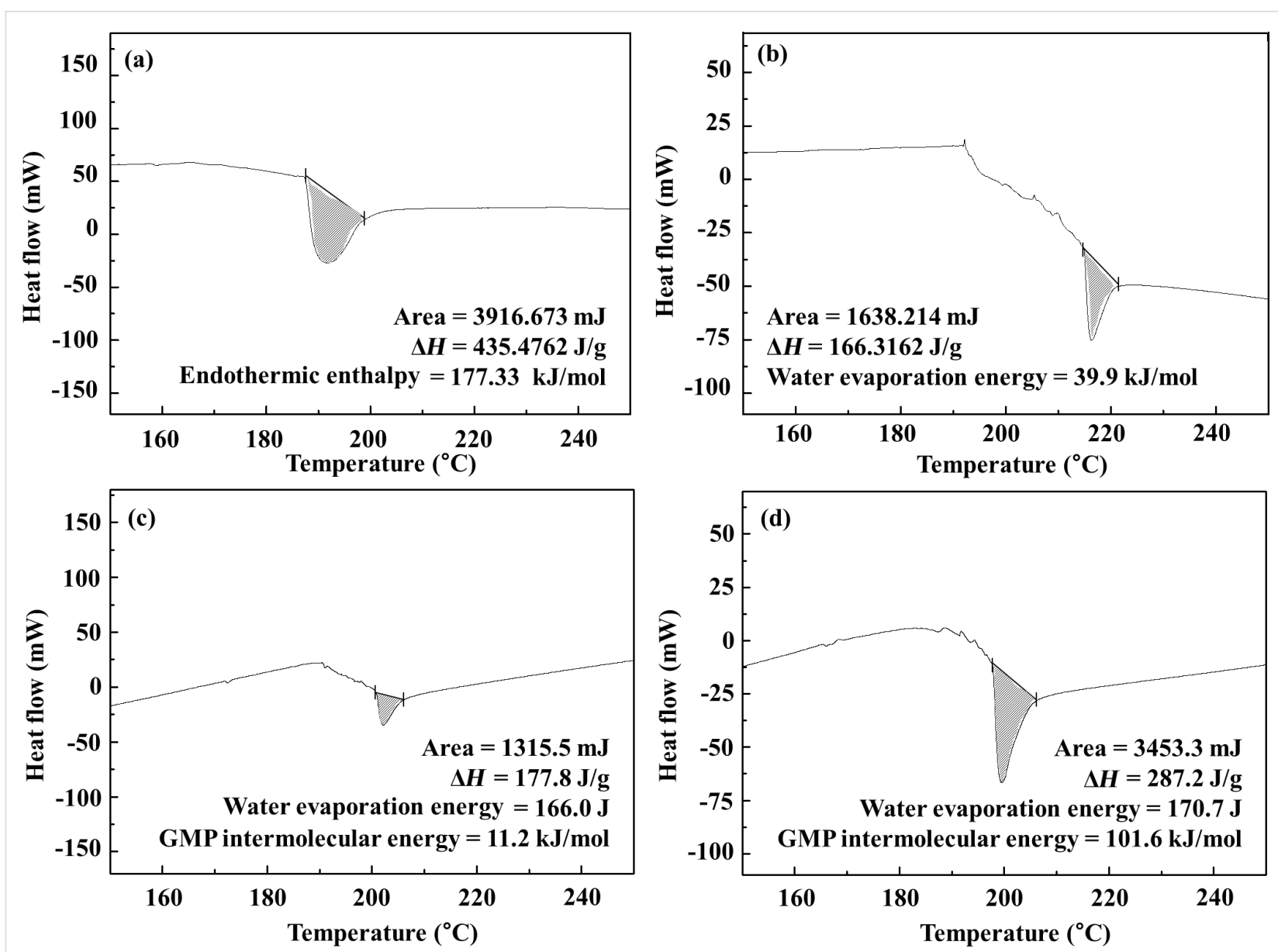

Figure 5: Differential scanning calorimetry (DSC) diagrams of (a) GMP powder, (b) pristine MgAl-NO $3-\mathrm{LDH}$, (c) GL-S and (d) GL-R.

supramolecular structure in GL-R was asymmetric and possibly ribbon-like. In order to verify that the intact structure of GMP is preserved after intercalation into $\mathrm{LDH}$, we carried out Fourier transform infrared (FTIR) spectroscopy. As shown in Figure 6a, GMP (a) shows typical vibrational modes at 1695, 1605, 1535, and $1365 \mathrm{~cm}^{-1}$, which were attributed to $\mathrm{C}=\mathrm{O}, \mathrm{C}=\mathrm{N}$, pyrimidine/imidazole and imidazole vibration, respectively. Two bands at 1080 and $980 \mathrm{~cm}^{-1}$ resulted from $\mathrm{PO}_{3}{ }^{2-}$ antisymmetric stretching and $\mathrm{PO}_{3}{ }^{2-}$ symmetric stretching [19]. Both GL-S (Figure 6a, line c) and GL-R (Figure 6a, line d) showed similar IR bands compared with GMP only, although the bands in the range $1550-1800 \mathrm{~cm}^{-1}$ could not be separated in detail due to the merging with the $\delta$-mode of interlayer water $\left(1640 \mathrm{~cm}^{-1}\right)$. Particle morphologies of GL hybrids are displayed in Figure 6b. Both images showed LDH particles with homogeneous size distribution. The average particle size was determined to be $\approx 90 \mathrm{~nm}$ and $\approx 50 \mathrm{~nm}$ for GL-S and GL-R, respectively. The slightly larger size of GL-S was attributed to the aging effect in inorganic particles [20], as GL-S was heated to $80^{\circ} \mathrm{C}$. Compared to the SEM image of the GMP reagent and pristine LDH (Supporting Information File 1, Figure S3), we verified that the particle morphology of both GL hybrids exhibited a typical pattern of organic moiety intercalated LDHs. Disk-shaped particles were agglomerated due to the particleedge interaction between LDH particles [21].

We confirmed that interlayer arrangements of GMP molecules, such as single molecular or ribbon orientation, could be obtained according to specific synthetic conditions. As a further step, we tried to verify whether the interlayer arrangement could be converted to the other phase by adjusting the external conditions. The addition of LDH while heating was thought to convert GL-R to GL-S as the condition disrupts hydrogen bonding and provides more interlayer space, allowing molecules to be isolated. As shown in Figure 7a, one day of stirring at $80^{\circ} \mathrm{C}$ with the addition of 1 equivalent $\mathrm{LDH}$ showed the evolution of the (003) peak at $7^{\circ}$ (Figure $7 \mathrm{a}$, line b), which corresponded to the interlayer space of single molecule arrangement. After two days, the (003) peak corresponding to the ribbon orientation almost disappeared and the peak at $7^{\circ}$ became dominant, implying that the GL-R was converted into GL-S. In order to convert GL-S to GL-R, we applied a similar strategy. One 


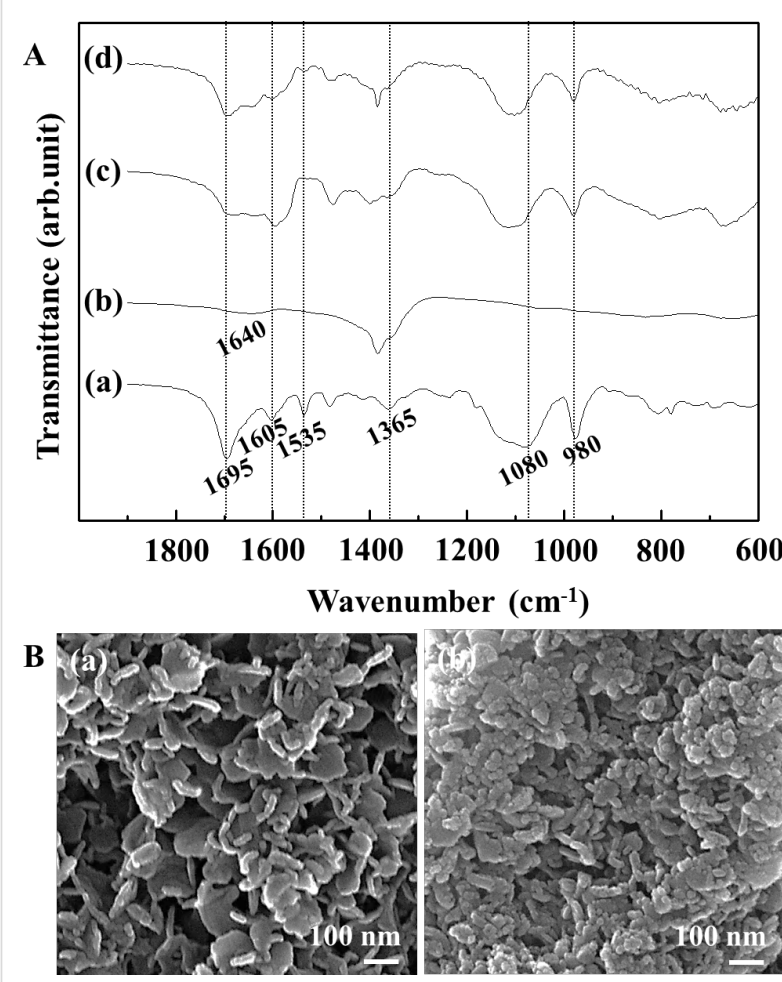

Figure 6: (a) Fourier transformed infrared (FTIR) spectra of GMP powder (line a), pristine MgAl-NO $\mathrm{N}_{3}-\mathrm{LDH}$ (line b), GL-S (line c) and GL-R hybrid (line d). (b) Scanning electron microscopic (SEM) images of GL-S (image a) and GL-R hybrid (image b).

equivalent of GMP was added in solution phase to the GL-S suspension, while the temperature was set to $20^{\circ} \mathrm{C}$. According to Figure $7 \mathrm{~b}$ (line b), the intensity of (003) for GL-S decreases after one day of stirring and a new peak at $4.8^{\circ}$, which matched with that for GL-R, began to appear. After two days, we could obtain XRD patterns corresponding to GL-R. These results suggested that the surrounding conditions switch the stable interlayer molecular orientation of GMP.

\section{Conclusion}

GMP was intercalated into the interlayer space of LDH (GL hybrids) and its molecular arrangement was controlled to form in either single molecular orientation or ribbon-type supramolecular assembly according to synthetic conditions. At high temperature $\left(80\right.$ and $\left.100{ }^{\circ} \mathrm{C}\right)$, GMPs were separated in single molecules and at low temperature $\left(20,40\right.$, and $\left.60^{\circ} \mathrm{C}\right)$, GMPs assembled in a ribbon structure. The intermolecular energy for GMP, $\approx 101 \mathrm{~kJ} / \mathrm{mol}$, suggested the possibility of double hydrogen bond between GMPs in GL-R. We also verified that, once stabilized, GL-S or GL-R could be converted to the other phases by adjusting synthetic conditions like stoichiometry and temperature. The stoichiometry between the LDH and GMP determined interlayer molecular packing patterns, which in turn influenced intermolecular interaction among GMP molecules.
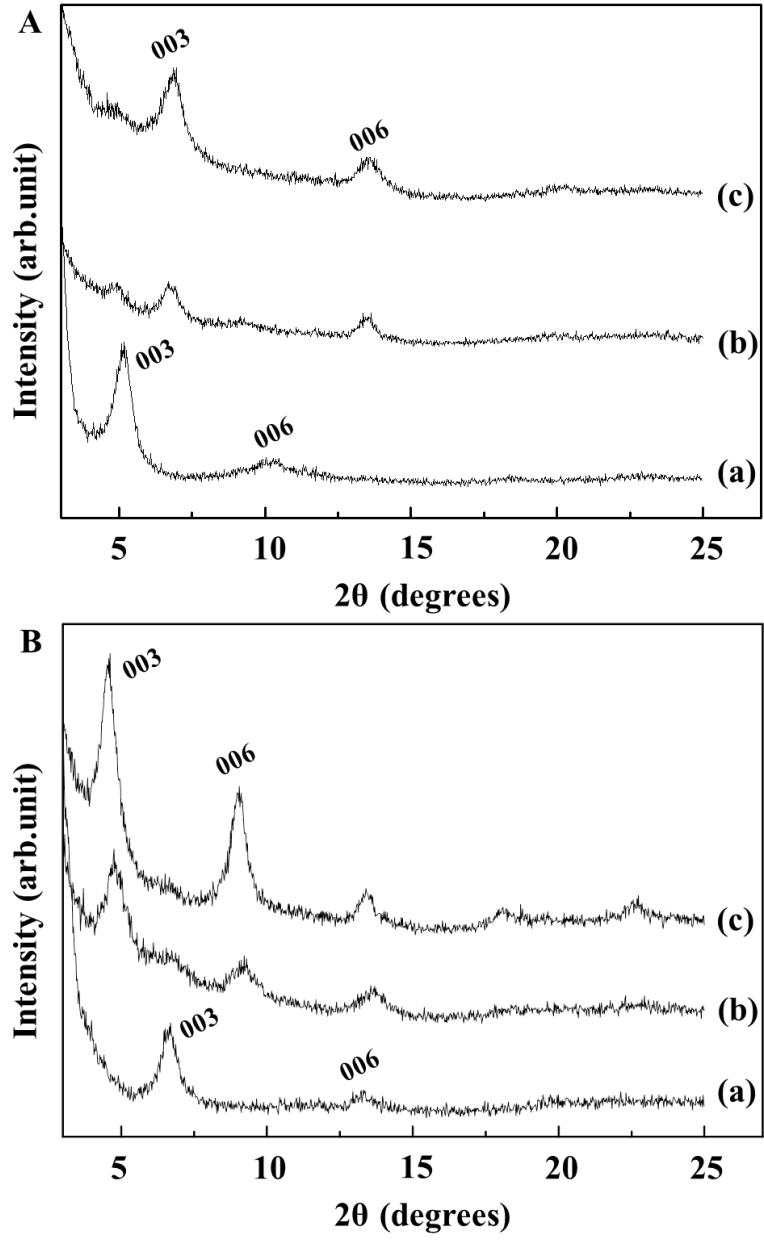

Figure 7: X-ray diffraction (XRD) patterns of GL hybrids obtained by interconverting interlayer GMP arrangement. (a): GL-R to GL-S and (b): GL-S to GL-R, for starting (line a), intermediate (line b) and final (line c) products.

Furthermore, even in confined space, the temperature affected the formation and breakage of hydrogen bonds.

\section{Experimental}

\section{Materials}

Magnesium nitrate hexahydrate $\left(\mathrm{Mg}\left(\mathrm{NO}_{3}\right)_{2} \cdot 6 \mathrm{H}_{2} \mathrm{O}\right)$ and aluminum nitrate nonahydrate $\left(\mathrm{Al}\left(\mathrm{NO}_{3}\right)_{3} \cdot 9 \mathrm{H}_{2} \mathrm{O}\right)$ were purchased from Sigma-Aldrich (St. Louis, USA). Guanosine 5'-monophosphate disodium salt hydrate $\left(\mathrm{C}_{10} \mathrm{H}_{12} \mathrm{~N}_{5} \mathrm{Na}_{2} \mathrm{O}_{8} \mathrm{P} \cdot x \mathrm{H}_{2} \mathrm{O}\right)$ was purchased from Tokyo Chemical Industry Co., Ltd. (Tokyo, Japan). Sodium hydroxide $(\mathrm{NaOH})$ in pellet form was purchased from Daejung Chemicals \& Metals Co., Ltd. (Siheungsi, Gyonggi-do, Korea).

\section{Preparation of pristine $\mathrm{MgAl}-\mathrm{NO}_{3}-\mathrm{LDH}$}

An aqueous solution in which $\mathrm{Mg}\left(\mathrm{NO}_{3}\right)_{2} \cdot 6 \mathrm{H}_{2} \mathrm{O}(0.45 \mathrm{M}$, $45 \mathrm{mmol})$ and $\mathrm{Al}\left(\mathrm{NO}_{3}\right)_{3} \cdot 9 \mathrm{H}_{2} \mathrm{O}(0.225 \mathrm{M}, 22.5 \mathrm{mmol})$ were dis- 
solved in decarbonated water was titrated with $\mathrm{NaOH}(0.75 \mathrm{M})$ solution up to $\mathrm{pH} \approx 9.5$. After a white-colored suspension was formed, the reaction was kept stirring for $24 \mathrm{~h}$. The obtained $\mathrm{MgAl}-\mathrm{NO}_{3}-\mathrm{LDH}$ sample was centrifuged and thoroughly washed with decarbonated water.

\section{Preparation of GL hybrids}

$\mathrm{MgAl}-\mathrm{NO}_{3}-\mathrm{LDH}$ was dispersed in decarbonated water to achieve a $\approx 0.06 \mathrm{~g} / \mathrm{mL}$ concentration. In order to intercalate GMP into LDH (GL hybrid), two parameters, the GMP/Al ${ }^{3+}$ (in $\mathrm{LDH})$ molar ratio and reaction temperature, were controlled individually. For the molar ratio control experiment, $0.186 \mathrm{mmol}$ of GMP $(0.07582 \mathrm{~g})$ was dissolved in $10 \mathrm{~mL}$ of decarbonated water at $80{ }^{\circ} \mathrm{C}$. Then $\mathrm{LDH}$ suspensions of 0.25 , $0.5,1,2,4$, and 10 equiv $\mathrm{Al}^{3+}$ were added to the GMP solution and stirred for one day at $80{ }^{\circ} \mathrm{C}$ under $\mathrm{N}_{2}$ atmosphere. For the temperature control measurement, a GMP/Al ${ }^{3+}$ (in LDH) molar ratio 1:2 was chosen and mixtures were reacted at 20, 40, 60, 80 , and $100{ }^{\circ} \mathrm{C}$, respectively, for one day. We found optimized preparation conditions for GL-S (GL hybrid with single molecular GMP orientation) and GL-R (GL hybrid with ribbon phase GMP structure) hybrid as follows. GMP/LDH molar ratio 1:2, reaction temperature $80{ }^{\circ} \mathrm{C}$ and two days reaction time for GL-S; GMP/LDH molar ratio $1: 1$, reaction temperature $20^{\circ} \mathrm{C}$ and one day reaction for GL-R hybrid.

\section{Conversion of interlayer GMP arrangement}

In order to convert GL-R to GL-S, 1 equiv of LDH suspension was added to the GL-R suspension at $80{ }^{\circ} \mathrm{C}$ and was stirred for one day. For the reverse reaction (GL-S to GL-R), 1 equiv of GMP was added to the GL-S suspension at room temperature under stirring for two days.

\section{Characterization}

All the samples were thoroughly washed with decarbonated water and lyophilized before characterization. The adsorption isotherm experiment was carried out with a UV-vis spectrophotometer (UV-vis; Shimadzu UV-1800, Shimadzu Corporation, Kyoto, Japan) at $\lambda_{\max }=253 \mathrm{~nm}$. In order to identify the crystal structure of pristine LDH and to evaluate the lattice expansion of LDH along the $c$-axis upon GMP intercalation, X-ray diffraction patterns (XRD) were obtained with a Bruker D2 instrument with $\mathrm{Ni}$-filtered $\mathrm{Cu} \mathrm{K} \alpha$ radiation $(\lambda=1.5406 \AA)$. The hydrogen bonding of the GL-R hybrid was verified by differential scanning calorimetry diagrams (DSC, PerkinElmer DSC 8000 ) with $5 \% \mathrm{~min}$ heating rate. To investigate the intact structure and intermolecular interaction of GMP in GL hybrids, Fourier transform-infrared spectra (FTIR, PerkinElmer, Spectrum One) with conventional $\mathrm{KBr}$ pellet method was carried out. The morphology of GL hybrids was observed by scanning electron microscopic (SEM) images obtained with an FEI
QUANTA 250 FEG. For quantitative analysis, a thermogravimetric analyzer (TGA, SINCO STA S-1000) and X-ray fluorescence spectrometer (XRF, Thermo Scientific ARL QUANT'X) were used.

\section{Supporting Information}

\section{Supporting Information File 1}

Adsorption isotherm, theoretical Langmuir plots, solid-state NMR spectra, and additional SEM images.

[http://www.beilstein-journals.org/bjnano/content/ supplementary/2190-4286-7-184-S1.pdf]

\section{Acknowledgements}

This work was supported by a grant from International Research \& Development Program (NRF2014K1A3A1A21001297) through the National Research Foundation of Korea (NRF) funded by the Ministry of Science, ICT, and Future Planning, Republic of Korea. This work was conducted within the framework of ANR DYNAMULTIREC and PHC STAR Program no. 32153VJ, France.

\section{References}

1. Bernal, J. D. Proc. Phys. Soc., London, Sect. A 1949, 62, 537. doi:10.1088/0370-1298/62/11/512

2. Cairns-Smith, A. G. FEBS Lett. 1983, 154, 219-220. doi:10.1016/0014-5793(83)80911-9

3. Choy, J.-H.; Kwak, S.-Y.; Park, J.-S.; Jeong, Y.-J.; Portier, J. J. Am. Chem. Soc. 1999, 121, 1399-1400. doi:10.1021/ja981823f

4. Nakayama, H.; Wada, N.; Tsuhako, M. Int. J. Pharm. 2004, 269, 469-478. doi:10.1016/j.jpharm.2003.09.043

5. Whilton, N. T.; Vickers, P. J.; Mann, S. J. Mater. Chem. 1997, 7, 1623-1629. doi:10.1039/a701237c

6. Jaber, M.; Georgelin, T.; Bazzi, H.; Costa-Torro, F.; Lambert, J.-F.; Bolbach, G. R.; Clodic, G. J. Phys. Chem. C 2014, 118, 25447-25455. doi:10.1021/jp507335e

7. Burcar, B. T.; Jawed, M.; Shah, H.; McGown, L. B. Origins Life Evol. Biospheres 2015, 45, 31-40. doi:10.1007/s11084-015-9412-y

8. Gottarelli, G.; Masiero, S.; Mezzina, E.; Pieraccini, S.; Rabe, J. P.; Samorí, P.; Spada, G. P. Chem. - Eur. J. 2000, 6, 3242-3248. doi:10.1002/1521-3765(20000901)6:17<3242::AID-CHEM3242>3.0.C $\mathrm{O} ; 2-\mathrm{K}$

9. Peters, G. M.; Skala, L. P.; Plank, T. N.; Hyman, B. J.; Manjunatha Reddy, G.; Marsh, A.; Brown, S. P.; Davis, J. T. J. Am. Chem. Soc. 2014, 136, 12596-12599. doi:10.1021/ja507506c

10. Arnal-Hérault, C.; Pasc, A.; Michau, M.; Cot, D.; Petit, E.; Barboiu, M. Angew. Chem., Int. Ed. 2007, 46, 8409-8413. doi:10.1002/anie.200702605

11. Leroux, F.; Besse, J.-P. Chem. Mater. 2001, 13, 3507-3515. doi:10.1021/cm0110268

12. Lee, J.-Y.; Gwak, G.-H.; Kim, H.-M.; Kim, T.-i.; Lee, G. J.; Oh, J.-M. Appl. Clay Sci. 2016, 134, 44-49. doi:10.1016/j.clay.2016.03.029 
13. Cavani, F.; Trifirò, F.; Vaccari, A. Catal. Today 1991, 11, 173-301. doi:10.1016/0920-5861(91)80068-K

14. Choy, J.-H.; Jung, J.-S.; Oh, J.-M.; Park, M.; Jeong, J.; Kang, Y.-K.; Han, O.-J. Biomaterials 2004, 25, 3059-3064. doi:10.1016/j.biomaterials.2003.09.083

15. Tammaro, L.; Vittoria, V.; Bugatti, V. Eur. Polym. J. 2014, 52, 172-180. doi:10.1016/j.eurpolymj.2014.01.001

16. Williamson, J. R.; Raghuraman, M.; Cech, T. R. Cell 1989, 59 871-880. doi:10.1016/0092-8674(89)90610-7

17. Berg, J. M.; Tymoczko, J. L.; Stryer, L. Biochemistry; W.H. Freeman \& Co. Ltd., 2006.

18. Madariaga, S. T.; Contreras, J. G. J. Chil. Chem. Soc. 2010, 55, 50-52. doi:10.4067/S0717-97072010000100012

19. Kumar, A.; Gupta, S. K. J. Mater. Chem. B 2013, 1, 5818-5830. doi:10.1039/c3tb20877j

20. Nývlt, J.; Söhnel, M.; Matachová, M.; Broul, M. The kinetics of industrial crystallization; Elsevier Science Ltd, 1985; pp $334 \mathrm{ff}$.

21. Kim, T.-H.; Lee, G. J.; Kang, J.-H.; Kim, H.-J.; Kim, T.-i.; Oh, J.-M. BioMed Res. Int. 2014, 2014, 193401. doi:10.1155/2014/193401

\section{License and Terms}

This is an Open Access article under the terms of the Creative Commons Attribution License (http://creativecommons.org/licenses/by/4.0), which permits unrestricted use, distribution, and reproduction in any medium, provided the original work is properly cited.

The license is subject to the Beilstein Journal of

Nanotechnology terms and conditions:

(http://www.beilstein-journals.org/bjnano)

The definitive version of this article is the electronic one which can be found at:

doi:10.3762/bjnano.7.184 